\title{
Subject Digital Photograph Report
}

National Cancer Institute

\section{Source}

National Cancer Institute. Subject Digital Photograph Report. NCI Thesaurus. Code

C115516.

Records pertaining to the findings from a study subject's digital photograph images. 